\title{
JUMLAH TEMPAT PENELURAN PENYU HIJAU (Chelonia mydas) BERDASARKAN VEGETASI PANTAI DI TAMAN WISATA ALAM (TWA) TANJUNG BELIMBING KECAMATAN PALOH KABUPATEN SAMBAS
}

(number of green sea turtle (Chelonia mydas) nesting sites based on coastal vegetation in Tanjung Belimbing Nature Tourism Park (TWA) Paloh District Sambas Regency)

\author{
Wawan Kurniawan, Erianto, Iswan Dewantara \\ Fakultas Kehutanan Universitas Tanjungpura, Jalan Imam Bonjol Pontianak, 78124 \\ E-mail: wawan.kurniawan.0201@gmail.com
}

\begin{abstract}
The decline in the population of green sea turtles (Chelonia mydas) occurs continuously due to the destruction of the nesting beach habitat, therefore efforts are needed to increase the green sea turtle population by rearranging nesting sites. One thing that is considered important from the green sea turtle nesting habitat is the coastal vegetation. This research was conducted in Tanjung Belimbing Nature Tourism Park, Sambas Regency, West Kalimantan Province. This study aims to obtain information on vegetation conditions that are preferred by green sea turtles to lay eggs through the number of nesting sites approach. The method used is a survey method. Data collection was carried out by direct observation in the field. In this study, 12 nesting sites were found spread over four observation sites, with the highest number of nesting site found at observation location 1 as many as 8 nesting sites. At observation location 1, besides cemara laut (Casuarina equisetifolia) and pandan laut (Pandanus tectorius) also found waru (Hibiscus tiliaceus) and api-api (Avicennia sp) as well as shrub plants such as kamboja laut (Scaevola taccada), serunai laut (Melanthera biflora) ) and herbal plants such as tapak kuda (Ipomoea pescaprae), alaban tanah (Vitex rotundifolia), rumput tembaga (Ischaemum muticum), bayam berduri (Amaranthus sp) and bakung laut (Crynum asiaticum L).
\end{abstract}

Keywords: Nesting Sites, Vegetation, Green sea turtle, Tanjung Belimbing Nature Tourism Park

\section{PENDAHULUAN}

Indonesia merupakan negara yang kaya akan spesies penyu dari tujuh spesies penyu yang ada di dunia enam diantaranya berada di perairan Indonesia yaitu, penyu hijau (Chelonia mydas), penyu sisik (Eretmochelys imbricata), penyu abu-abu (lekang) (Lepidochelys olivacea), penyu pipih (Natator depressus), penyu belimbing (Dermochelys coriacea), serta penyu tempayan (Caretta caretta). Satu jenis penyu yang tidak ditemukan di perairan Indonesia adalah penyu kempi (Lepidocheyls kempi) yang hanya ditemukan di perairan Amerika (Dahuri, 2003). Wilayah pesisir pantai di Indonesia yang merupakan salah satu habitat bagi enam jenis penyu, diantaranya tersebar di wilayah perairan Bali, Jawa Barat, Jawa Timur, Kalimantan Timur, Irian Jaya dan Kalimantan Barat (Anshary et al., 2014). Salah satu jenis penyu yang paling banyak ditemukan di kawasan Kalimantan Barat adalah penyu hijau (Chelonia mydas). Jenis ini dapat ditemukan diseluruh perairan bagian tropis dan subtropis diseluruh dunia dengan ciri yang mudah dikenali yaitu 
bentuk paruh yang kecil dan tumpul (Dewi et al., 2016).

Taman Wisata Alam (TWA) Tanjung Belimbing merupakan salah satu kawasan konservasi yang terletak di Kalimantan Barat sebagai habitat penyu dengan aktivitas bertelurnya. Lokasi ini sering ditemukan aktivitas penyu yang mendarat ataupun bertelur sebagian besar merupakan jenis penyu hijau (Chelonia mydas), TWA ini didominasi oleh tipe ekosistem hutan mangrove dan hutan pantai. Vegetasi pada hutan pantai didominasi oleh cemara laut (Casuarina equisetifolia), tetapi dibeberapa daerah disepanjang pesisir di TWA ini juga terdapat vegetasi yang dominasi seperti kelapa (Cocos nucifera), nipah (Nypa fruticans), waru (Hibiscus tiliaceus), pandan laut (Pandanus tectorius) dan tumbuhan merambat seperti tapak kuda (Ipomea pes-caprae). Kawasan ini juga memiliki pantai yang cukup landai dengan warna pasir putih kecoklatan serta ombak yang tidak pernah putus, selain menjadi habitat peneluran penyu sekaligus menjadi kawasan penangkaran penyu, kawasan ini juga sebagai perlindungan pantai dari pukulan gelombang laut, sumber makan dan pertumbuhan bagi spesies-spesies biota laut (Balai KSDA KalBar, 2011).

Menurut Pradana et al. (2013), populasi penyu hijau (Chelonia mydas) terus menurun yang disebabkan oleh pencurian telur, maraknya aktivitas nelayan disekitar pantai peneluran dan banyaknya vegetasi yang rusak/tumbang akibat terjadinya abrasi pantai, sehingga penyu enggan mau mendarat untuk bertelur. Agar habitat peneluran penyu hijau ( $C$. mydas) tidak rusak baik fisik dan morfologi penyusun pantainya maka perlu dikelola dengan baik dan terkendali, jika ekosistem pantai tempat peneluran penyu tidak terjaga, tentu secara tidak langsung akan berpengaruh pada proses perkembangbiakan penyu. Mengingat kekayaan sumber daya alam berupa satwa liar, peran, dan manfaat yang begitu penting maka perlu upaya untuk meningkatkan populasi penyu hijau dengan melakukan penataan kembali tempat peneluran (nesting site). Salah satu yang dianggap penting dari habitat peneluran penyu hijau ialah vegetasi pantai, karena adanya vegetasi pantai dapat menjaga kestabilan suhu dan tingkat kelembaban serta menghindari dari predator dalam suatu area tempat peneluran penyu hijau $(C$. mydas).

Informasi dan data yang menjelaskan terkait tentang jumlah tempat peneluran penyu hijau (Chelonia mydas) berdasarkan vegetasi pantai di TWA Tanjung Belimbing saat ini, belum ada data mengenai hal tersebut. Maka dari itu perlu dilakukan penelitian ini, sehingga dapat melihat pengaruh jumlah pendaratan penyu hijau (C. mydas) terhadap jenis-jenis vegetasi pantai yang terdapat di TWA Tanjung Belimbing, sehingga dapat memberikan informasi ilmiah dalam upaya konservasi penyu hijau di TWA Tanjung Belimbing.

Penelitian ini bertujuan untuk mendapatkan informasi tentang jumlah tempat peneluran penyu hijau (Chelonia mydas) berdasarkan vegetasi pantai di 
TWA Tanjung Belimbing. Adapun manfaat dari penelitian ini diharapkan dapat memberikan informasi ilmiah khususnya bagi Balai KSDA Kalimantan Barat dalam pengelolaan habitat peneluran penyu hijau dan pembinaan tumbuhan di kawasan TWA Tanjung Belimbing, serta menjadi dasar acuan bagi pelaku konservasi dalam manajemen konservasi penyu di Paloh.

\section{METODE PENELITIAN}

Penelitian ini dilaksanakan dengan metode survei dari tanggal 15 Juli 2019 sampai tanggal 28 Juli 2019 di Taman
Wisata Alam (TWA) Tanjung Belimbing Kecamatan Paloh Kabupaten Sambas Provinsi Kalimantan Barat. Pengumpulan data dilakukan dengan cara observasi langsung dilapangan. Pantai peneluran penyu di TWA Tanjung Belimbing memiliki panjang $\pm 6,894$ $\mathrm{Km}$. Jumlah lokasi pengamatan dibuat sebanyak 4 (empat) lokasi pengamatan dengan kondisi lingkungan yang berbeda berdasarkan vegetasi pantai yang didominasi pada tempat peneluran penyu hijau (Chelonia mydas).

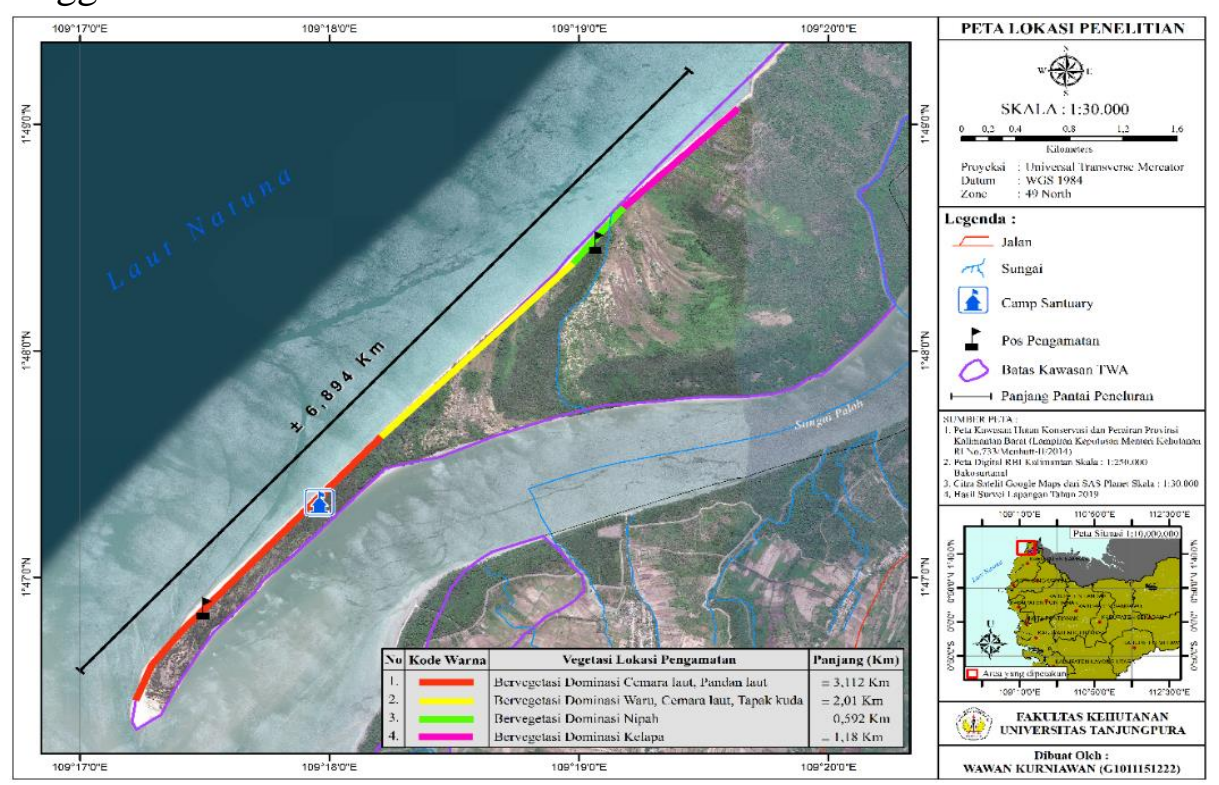

Gambar 1. Peta Lokasi Penelitian (Research Map Location)

\section{Alat dan Bahan Penelitian}

Alat yang digunakan dalam penelitian ini adalah sebagai berikut: peta lokasi penelitian, ATK, GPS (Global Positioning System), meteran roll, thermometer, higrometer, waterpass, tongkat skala $2 \mathrm{~m}$, head lamp, kamera, patok, tali rafia, pita ukur, kunci determinasi, dan tally sheet.

\section{Prosedur Penelitian}

Lokasi penelitian dibagi 4 lokasi pengamatan. Penentuan lokasi pengamatan dilakukan secara purposive dengan didasarkan pada keberadaan tempat peneluran dan adanya aktivitas bertelur dari penyu hijau (Chelonia mydas). Untuk analisis vegetasi pantai berdasarkan tempat peneluran penyu hijau menggunakan metode petak berukuran $20 \mathrm{~m}$ x $20 \mathrm{~m}$.

\section{Teknik Pengumpulan Data}
a. Jumlah penyu hijau yang naik dan bertelur


Pencatatan jumlah penyu hijau yang naik dan bertelur dilakukan dengan menelusuri pantai disetiap lokasi pengamatan dan dilakukan pada malam hari mulai pada pukul 18.00 - 05.30 WIB, karena pada malam hari penyu sering ditemukan aktivitas peneluran.

\section{b. Struktur dan komposisi vegetasi} tempat peneluran penyu hijau

Pengamatan struktur dan vegetasi tempat peneluran penyu hijau (Chelonia myda)s dibuat petak-petak pengamatan ditiap tempat peneluran penyu hijau. Banyaknya petak pengamatan tergantung pada banyaknya tempat peneluran penyu hijau (C. mydas). Apabila jarak tempat peneluran berdekatan tidak dibuat petak pengamatan. Petak pengamatan dibuat empat buah plot yang terdiri atas plot berukuran $20 \mathrm{~m}$ x $20 \mathrm{~m}$ untuk vegetasi tingkat pohon, plot $10 \mathrm{~m} \times 10 \mathrm{~m}$ untuk vegetasi tingkat tiang, plot $5 \mathrm{~m} \times 5 \mathrm{~m}$ untuk vegetasi tingkat pancang dan semak, sedangkan plot $2 \mathrm{~m}$ x $2 \mathrm{~m}$ untuk vegetasi tingkat semai dan tumbuhan bawah seperti herba (Istomo dan Dwisutono, 2016). Desain metode analisis vegetasi pantai disajikan pada Gambar 2.

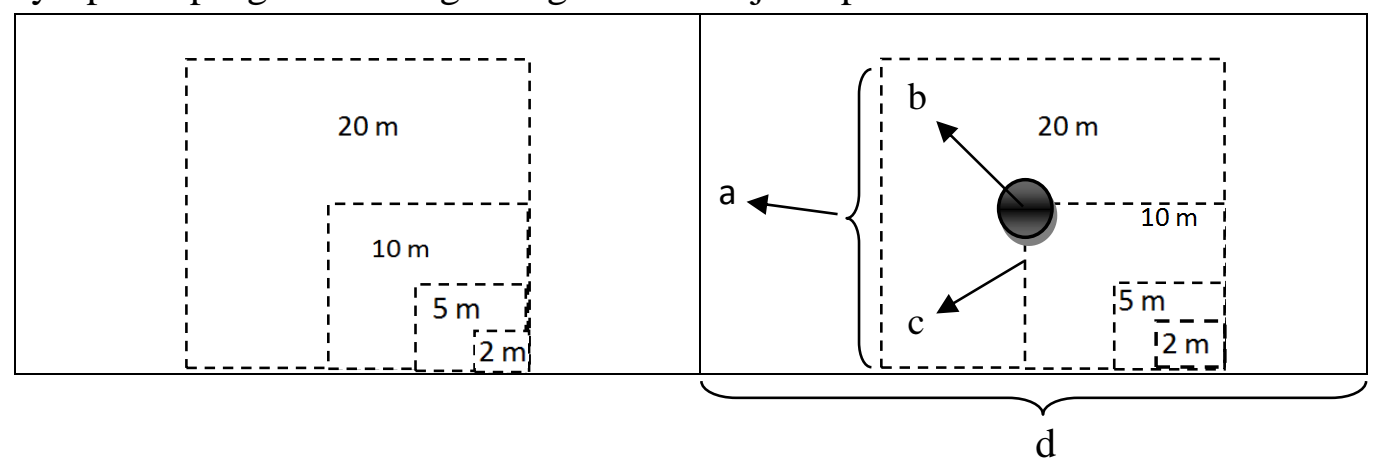

Gambar 2. (a). Petak pengamatan (b). Tempat peneluran penyu (c). Plot pengamatan

(d). Lokasi pengamatan ((a). Observation Swath (b). Green sea turtle nesting sites (c). Observation plot (d). Observation location)

c. Jarak tempat peneluran terhadap vegetasi

Pengukuran jarak tempat peneluran penyu hijau (Chelonia mydas) terhadap vegetasi dengan menggunakan meteran roll, dengan cara menarik garis tegak lurus dari tempat peneluran sampai kevegetasi yang menaungi tempat peneluran dan berada paling dekat keberadaannya terhadap tempat peneluran.

d. Jarak Tempat Peneluran Dari Pasang Naik Tertinggi

Pengukuran jarak tempat peneluran dari pasang naik tertinggi dengan menggunakan meteran roll, diukur dari pasang naik tertinggi dengan menarik tegak lurus hingga ke tempat peneluran penyu hijau (Chelonia mydas).

\section{e. Kemiringan Pantai}

Pengukuran kemiringan pantai dengan menggunakan meteran roll untuk mengukur panjang, tongkat berskala 2 meter untuk mengukur ketinggian yang diletakkan secara vertikal dan waterpass untuk mempertahankan kelurusan meteran roll. Pengukuran dimulai dari vegetasi terluar hingga ke pantai pertama kali 
basah oleh gelombang. Nilai kemiringan dihitung menggunakan rumus trigonometri.

\section{f. Tekstur Substrat}

Mengambil beberapa sampel pasir dibagian dasar sekitar tempat peneluran penyu hijau (Chelonia mydas) yang ditemukan ditiap lokasi pengamatan, kemudian pasir tersebut dimasukan ke dalam plastik sampel untuk dianalisis tekstur substratnya.

\section{g. Suhu dan Kelembaban}

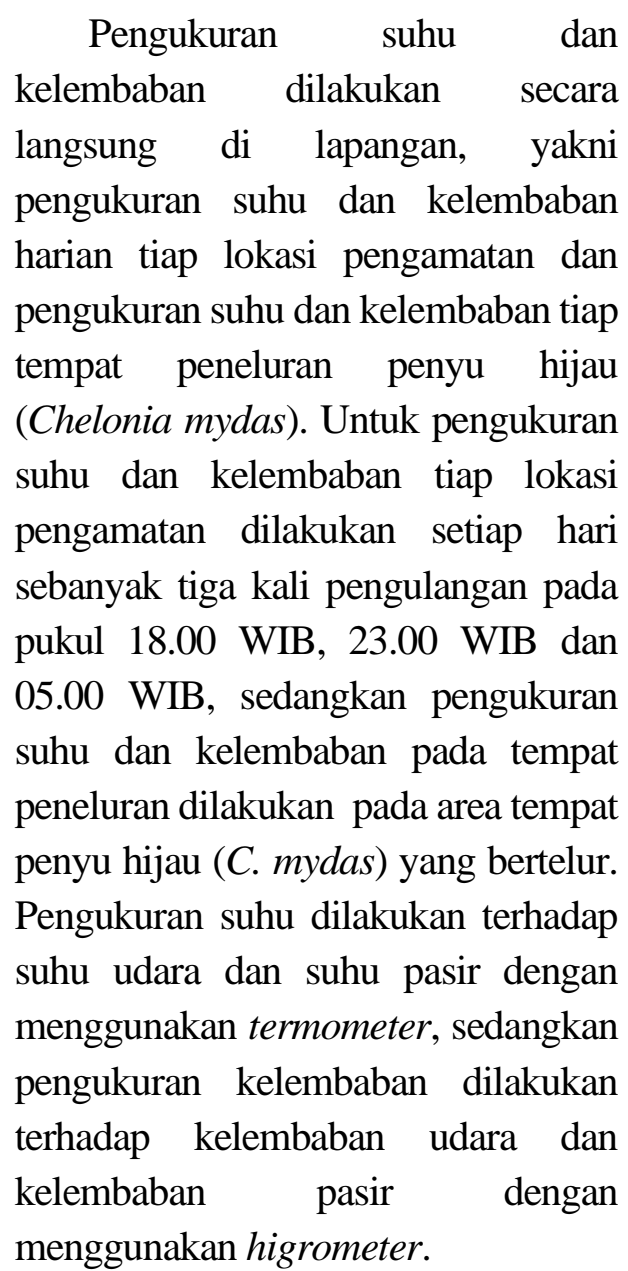

\section{h. Predator Telur dan Penyu}

Pengamatan predator dilakukan pada waktu siang dan malam hari dengan menelusuri sepanjang pesisir pantai ditiap lokasi pengamatan. Diamati dan didata setiap hewan dan predator lainnya yang berpotensi sebagai predator telur maupun penyu yang mendarat untuk melakukan aktivitas penelurannya, kemudian predator tersebut diidentifikasi.

\section{Analisis Data}

Analisis data yang dilakukan meliputi data jumlah tempat peneluran penyu hijau (Chelonia mydas), data kondisi biologi dan data kondisi fisik pantai peneluran. Data yang terkait dengan karakteristis fisik pantai dan jenis-jenis vegetasi pantai dianalisis secara kuantitatif. Data tersebut akan menunjukkan gambaran pengaruh vegetasi pantai di TWA Tanjung Belimbing terhadap tempat peneluran penyu hijau (C. mydas). Data analisis vegetasi yang telah dikumpulkan, kemudian diolah meliputi KR, FR, dan DR untuk mendapatkan nilai INP dari masingmasing spesies.

\section{HASIL DAN PEMBAHASAN}

\section{Kondisi Lingkungan Tiap Lokasi Pengamatan Penyu Hijau}

Berdasarkan pengamatan dan pengukuran yang dilakukan, terdapat perbedaan kondisi lingkungan pada masing-masing lokasi pengamatan (Tabel 1). 
Tabel 1. Kondisi lingkungan pada lokasi pengamatan (Environmental conditions at the observation location)

\begin{tabular}{|c|c|c|c|c|}
\hline \multirow{2}{*}{ Parameter } & \multicolumn{4}{|c|}{ Lokasi Pengamatan } \\
\hline & 1 & 2 & 3 & 4 \\
\hline $\begin{array}{l}\text { Vegetasi } \\
\text { Dominasi }\end{array}$ & $\begin{array}{l}\text { Cemara Laut } \\
\text { (Casuarina } \\
\text { equisetifolia), } \\
\text { Pandan Laut } \\
\text { (Pandanus } \\
\text { tectorius) }\end{array}$ & $\begin{array}{l}\text { Waru (Hibiscus } \\
\text { tiliaceus), Cemara } \\
\text { Laut (Casuarina } \\
\text { equisetifolia), } \\
\text { Tapak Kuda } \\
\text { (Ipomea pes- } \\
\text { caprae) }\end{array}$ & $\begin{array}{l}\text { Nipah (Nypa } \\
\text { fruticans) }\end{array}$ & $\begin{array}{l}\text { Kelapa (Cocos } \\
\text { nucifera) }\end{array}$ \\
\hline Panjang Pantai & $\pm 3,112 \mathrm{Km}$ & $\pm 2,01 \mathrm{Km}$ & $\pm 0,592 \mathrm{Km}$ & $\pm 1,18 \mathrm{Km}$ \\
\hline Lebar Pantai & $10-25 \mathrm{~m}$ & $10-20 \mathrm{~m}$ & $10-20 \mathrm{~m}$ & $10-20 \mathrm{~m}$ \\
\hline Kemiringan & $3 \%$ (Landai) & $5,5 \%$ (Landai) & $6,39 \%$ (Landai) & 7,11\% (Landai) \\
\hline Tekstur Pasir & $96,99 \%$ (Pasir) & $96,92 \%$ (Pasir) & $96,94 \%$ (Pasir) & $96,96 \%$ (Pasir) \\
\hline Suhu $\left({ }^{\circ} \mathbf{C}\right)$ & $\begin{array}{c}24,29-25,51 \\
\text { (Udara) } \\
\text { 24,84-25,65 } \\
\text { (Pasir) }\end{array}$ & $\begin{array}{c}25,54-26,05 \\
\text { (Udara) } \\
25,67-26,22 \\
\text { (Pasir) } \\
\end{array}$ & $\begin{array}{c}27,09-27,46 \\
\text { (Udara) } \\
27,23-27,64 \\
\text { (Pasir) } \\
\end{array}$ & $\begin{array}{c}\text { 27,19-27,76 } \\
\text { (Udara) } \\
\text { 27,34-27,89 } \\
\text { (Pasir) } \\
\end{array}$ \\
\hline $\begin{array}{c}\text { Kelembaban } \\
(\%)\end{array}$ & $\begin{array}{c}84,64-88,71 \\
\text { (Udara) } \\
85-88,21 \\
\text { (Pasir) }\end{array}$ & $\begin{array}{c}84,21-87,64 \\
\text { (Udara) } \\
83,21-87 \\
\text { (Pasir) }\end{array}$ & $\begin{array}{c}83,5-86,79 \\
\text { (Udara) } \\
83-86,79 \\
\text { (Pasir) } \\
\end{array}$ & $\begin{array}{l}84,21-87,29 \\
\text { (Udara) } \\
83,36-86,36 \\
\text { (Pasir) } \\
\end{array}$ \\
\hline
\end{tabular}

Berdasarkan Tabel 1 diketahui bahwa kondisi lingkungan dari empat lokasi pengamatan memiliki perbedaan, seperti vegetasi dominasi, panjang pantai, suhu dan kelembaban. Kondisi lingkungan lainnya seperti lebar pantai, kemiringan, dan tekstur pasir tidak terlalu signifikan antara empat lokasi pengamatan tersebut. Lokasi pengamatan 1 (bervegetasi dominasi cemara laut, pandan laut) merupakan lokasi pengamatan yang cukup panjang dibandingkan pada lokasi pengamatan lainnya dan jarang ditemukan predator, tetapi banyak vegetasi tumbang akibat abrasi pantai. Suhu lingkungan pada lokasi pengamatan ini sangat rendah dan kelembaban yang sangat tinggi dibandingkan pada lokasi pengamatan lainnya, karena vegetasi pada lokasi pengamatan ini banyak pohon-pohon besar dan rapat. Lokasi pengamatan 2 (bervegetasi dominasi waru, cemara laut, tapak kuda) kondisi lingkungannya hampir sama dengan lokasi pengamatan 1, tetapi terdapat tebing tinggi pada permukaan pantai akibat abrasi pantai. Suhu lingkungan pada lokasi pengamatan 2 cukup tinggi dibandingkan lokasi pengamatan 1 dan memiliki kelembaban pasir yang rendah dibandingkan pada lokasi pengamatan 3 dan 4, karena pada lokasi pengamatan ini vegetasi tingkat pohonnya sedikit dan banyak terdapat tumbuhan bawah seperti semak dan tumbuhan menjalar. Lokasi pengamatan 3 (bervegetasi dominasi nipah) merupakan lokasi pengamatan yang paling pendek dibandingkan pada lokasi pengamatan lainnya dan banyak ditemukan predator seperti babi hutan (Sus scrofa), biawak (Varanus salvator) serta banyak terdapat tebing tinggi pada permukaan pantai. Suhu 
lingkungan pada lokasi pengamatan 3 cukup tinggi dibandingkan pada lokasi pengamatan 2 dan memiliki kelembaban pasir yang cukup tinggi, karena pada lokasi pengamatan 3 tidak beragam jenis vegetasinya yaitu, hanya jenis tumbuhan nipah (Nypa fruticans) yang paling banyak ditemukan dan diduga di bawah hamparan pasir di lokasi ini masih terdapat substrat lumpur, sehingga menyebabkan kelembaban pasir di lokasi ini cukup tinggi dibandingkan pada lokasi pengamatan 2 dan 4. Lokasi pengamatan 4 (bervegetasi dominasi kelapa), kondisi lingkungannya juga terdapat predator seperti anjing peliharaan (Canis lupus familiaris) dan banyak terdapat tebing tinggi pada permukaan pantai. Suhu lingkungan pada lokasi pengamatan ini sangat tinggi dibandingkan lokasi pengamatan lainnya dan memiliki kelembaban pasir cukup rendah dibandingkan pada lokasi pengamatan 3 .

\section{Jumlah Penyu Hijau (Chelonia mydas)} Yang Naik dan Bertelur

Hasil pengamatan jumlah penyu hijau (Chelonia mydas) yang naik dan bertelur di kawasan TWA Tanjung Belimbing (Gambar 3).

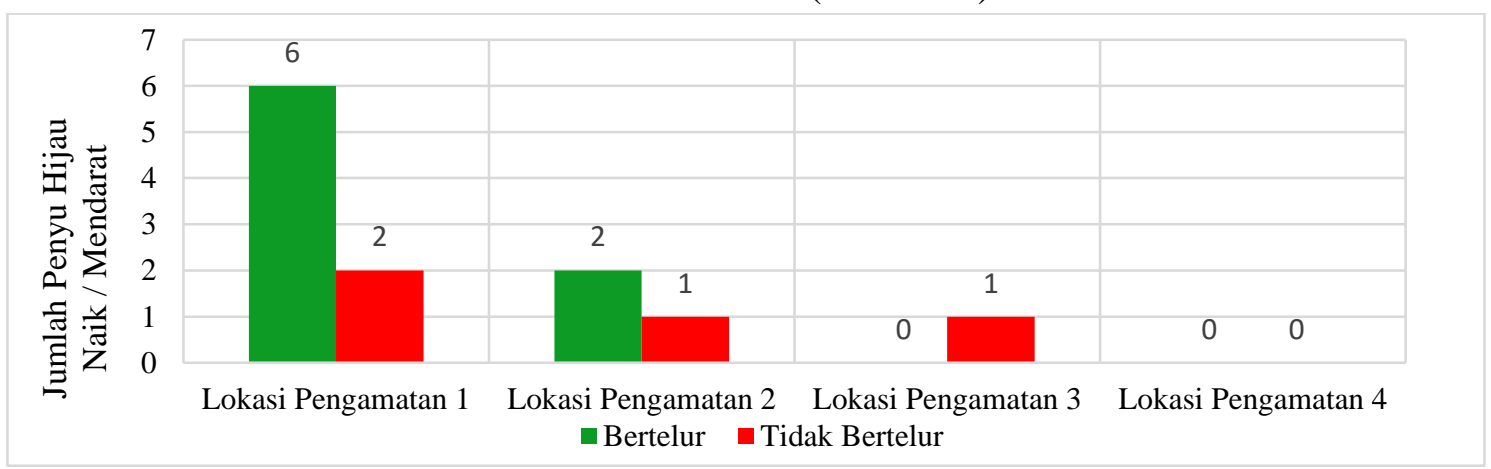

Gambar 3. Jumlah penyu hijau (Chelonia mydas) yang naik dan bertelur (Number of green sea turtle (Chelonia mydas) that land and lay eggs)

Berdasarkan data Gambar 3, menunjukkan bahwa penyu hijau (Chelonia mydas) yang paling banyak ditemukan yaitu, pada lokasi pengamatan 1 (bervegetasi dominasi cemara laut, pandan laut) sebanyak 8 ekor diantaranya 6 ekor yang bertelur dan 2 ekor tidak beretelur. Lokasi pengamatan yang sedikit ditemukannya aktivitas peneluran penyu hijau yaitu, pada lokasi pengamatan 2 (bervegetasi dominasi waru, cemara laut, tapak kuda) dan lokasi pengamatan 3 (bervegetasi dominasi nipah) yang dikarenkan pada lokasi pengamatan tersebut banyak ditemukannya tebing tinggi, predator, dan vegetasi tumbang akibat abrasi pantai oleh air laut yang membuat perubahan struktur habitat peneluran penyu hijau. Lokasi yang tidak ditemukannya aktivitas peneluran penyu hijau (C. mydas) yaitu, pada lokasi pengamatan 4 (bervegetasi dominasi kelapa) yang dikarenakan banyak tebing tinggi dipermukaan pantai yang berkisar 50-200 cm dan terdapat predator seperti anjing peliharaan (Canis lupus familiaris) yang selalu menjaga kebun kelapa, sehingga penyu hijau (C. mydas) merasa takut untuk mendarat. 


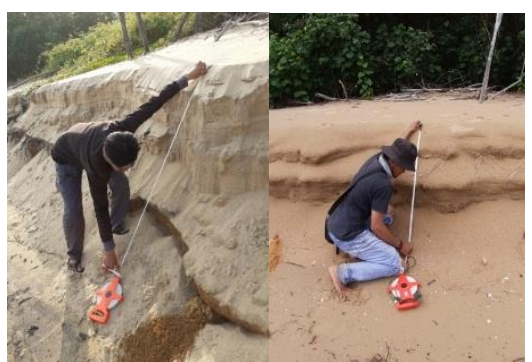

a

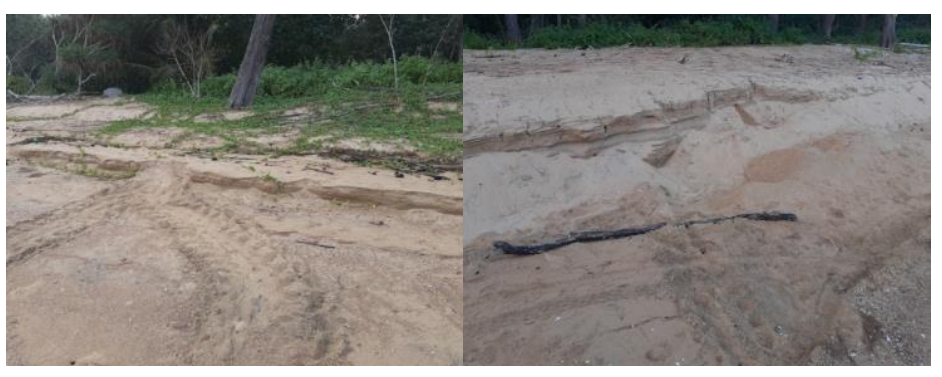

b

Gambar 4. (a). tebing pada pantai peneluran penyu hijau (Chelonia mydas) (b). track penyu hijau (C. mydas) tidak jadi mendarat/naik ((a). Cliffs on the green turtle nesting beach (Chelonia mydas) (b). Track of green sea turtle (C. mydas) that canceled its landing)

Struktur dan Komposisi Vegetasi Tempat Penluran Penyu Hijau (Chelonia mydas)

Hasil eksplorasi ploting berdasarkan letak tempat peneluran penyu hijau (Chelonia mydas) yang ditemukan pada lokasi pengamatan, ditemukan vegetasi sebanyak 12 spesies dan terdapat 615 individu yang berupa pohon, anak pohon, semak dan herba. Jumlah dan jenis vegetasi pantai tempat peneluran penyu hijau yang ditemukan di lokasi pengamatan disajikan pada Gambar 5.

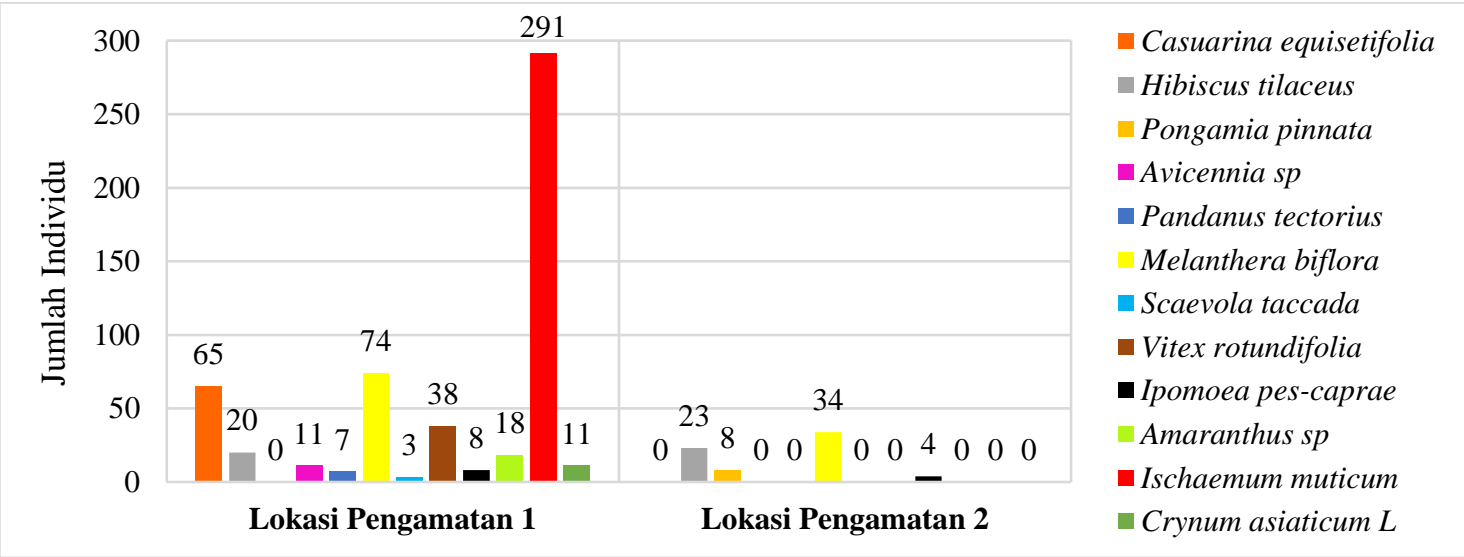

Gambar 5. Diagram jumlah dan jenis vegetasi pantai tempat peneluran penyu hijau (Chelonia mydas) (Diagram of the number and types of coastal vegetation at green sea turtles nesting sites (Chelonia mydas))

Hasil penelitian menunjukkan pada lokasi pengamatan 1 (bervegetasi dominasi cemara laut, pandan laut) terdapat 11 spesies dengan family yang berbeda. Jenis-jenis tersebut antara lain adalah jenis tumbuhan berkayu seperti cemara laut (Casuarina equisetifolia), waru (Hibiscus tiliaceus), dan api-api (Avicennia sp). Jenis tumbuhan semak seperti pandan laut (Pandanus tectorius), kamboja laut (Scaevola taccada) dan serunai laut (Melanthera biflora). Jenis tumbuhan herba seperti tapak kuda (Ipomoea pes-caprae), alaban tanah (Vitex rotundifolia), rumput tembaga (Ischaemum muticum), bayam berduri (Amaranthus sp) dan bakung laut (Crynum asiaticum L). Lokasi pengamatan 2 (bervegetasi dominasi waru, cemara laut dan tapak kuda) 
terdapat 4 spesies dengan family yang berbeda. Jenis-jenis tersebut antara lain adalah jenis tumbuhan berkayu seperti malapari (Pongamia pinnata) dan waru (Hibiscus tiliaceus), sedangkan jenis tumbuhan semak seperti serunai laut (Melanthera biflora) dan jenis tumbuhan herba seperti tapak kuda (Ipomoea pescaprae).

Struktur vegetasi merupakan penampakan susunan tegakan berdasarkan sebaran diameter, tingkat permudaan pancang, tiang, pohon, lapisan tajuk dan penyebaran dalam ruang (Fachrul, 2007). Indeks nilai penting jenis tumbuhan pada suatu komunitas merupakan salah satu parameter yang menunjukkan peranan jenis tumbuhan tersebut dalam komunitasnya. Semakin besar nilai INP suatu spesies semakin besar tingkat penguasaan terhadap komunitas dan sebaliknya.

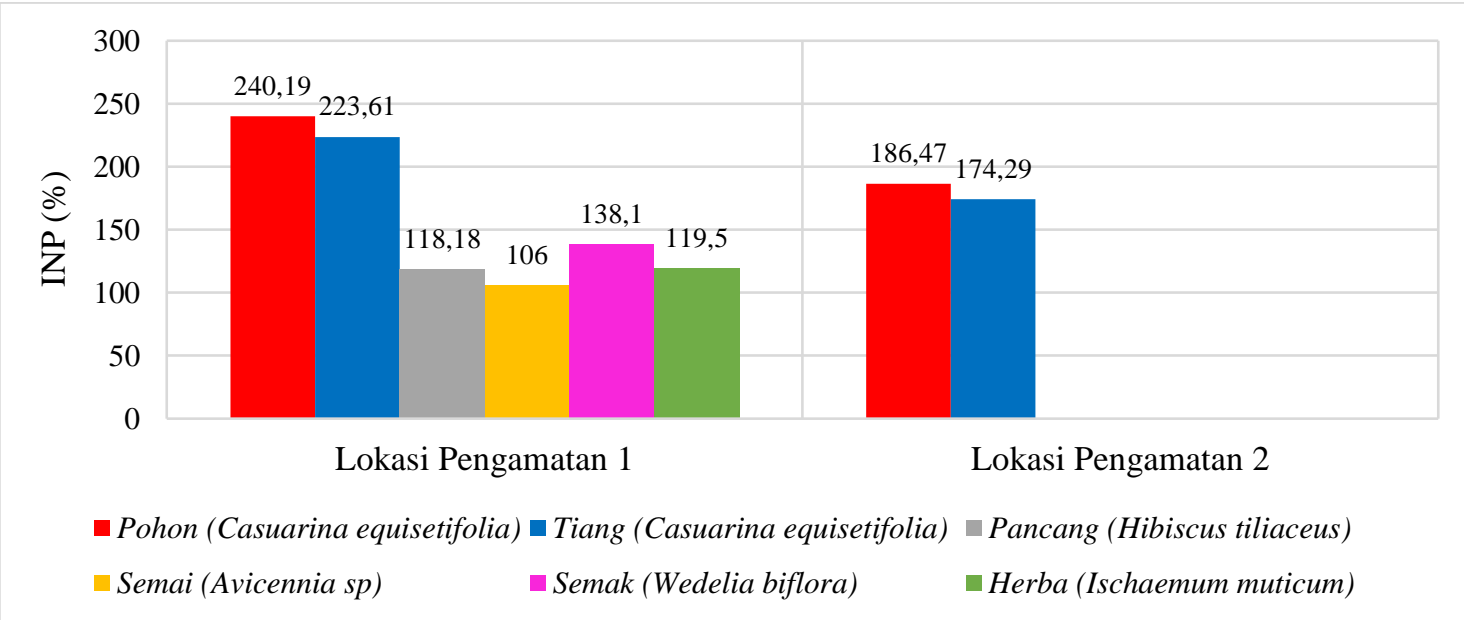

Gambar 6. Diagram nilai INP terbesar tiap tingkat pertumbuhannya (Diagram of the largest INP value for each growth rate)

Berdasarkan hasil data Gambar 6, menunjukkan nilai INP terbesar berturut didominasi pada lokasi pengamatan 1 (bervegetasi dominasi cemara laut, pandan laut). Tumbuhan pada strata pohon yaitu, cemara laut (Casuarina equisetifolia) dengan nilai INP = 204,19 $\%$, tumbuhan pada strata tiang yaitu, cemara laut (Casuarina equisetifolia) dengan nilai INP $=223,61 \%$, tumbuhan pada strata pancang yaitu, waru (Hibiscus tiliaceus) dengan nilai INP = $118,18 \%$, tumbuhan pada strata semai yaitu, api-api (Avicennia sp) dengan nilai
INP $=106 \%$, tumbuhan pada strata semak yaitu, serunai laut (Wedelia biflora) dengan nilai INP $=138,1 \%$, dan tumbuhan pada strata herba yaitu, rumput tembaga (Ischaemum muticum) dengan nilai INP $=119,5 \%$. Lokasi pengamatan 2 (bervegetasi dominasi waru, cemara laut, tapak kuda), jenis vegetasi tumbuhan bawahnya seperti tumbuhan strata semak dan herba hanya didapati 1 jenis pada lokasi pengamatan ini, karena pada saat pengamatan penyu hijau (Chelonia mydas) sedikit ditemukan aktivitas peneluran pada 
lokasi pengamatan ini dan kerapatan vegetasinya kurang dibandingkan pada lokasi pengamatan 1 .

Daerah tempat peneluran penyu hijau (C. mydas) diduga berhubungan erat dengan kondisi vegetasi terutama kerapatan yang berkaitan dengan penutupan vegetasi, dimana umumnya semakin rapat kondisi vegetasi maka penutupan vegetasinya juga semakin besar karena kerapatan vegetasi akan menghalangi intensitas cahaya yang masuk ke dasar vegetasi sehingga memberikan ketenangan atau rasa aman pada saat penyu hijau (C. mydas) akan bertelur menuju tempat peneluran. Vegetasi juga berpengaruh terhadap kestabilan suhu tempat peneluran penyu karena semakin tinggi penutupannya, maka semakin stabil suhu dalam tempat peneluran. Vegetasi akan mengurangi pengaruh langsung dari sinar matahari ke dalam tempat peneluran. Vegetasi juga berperan sebagai tempat berlindung penyu dari predator pada saat bertelur. Hal ini sesuai dengan pernyataan Nuitja (1992), yang menjelaskan bahwa penyu hijau cenderung memilih pantai dengan latar belakang yang bervegetasi sebagai tempat bertelurnya karena dapat memberikan ketenangan dan rasa aman bagi telur penyu/calon induk penyu mendatang.
Pemilihan lokasi tempat peneluran berdasarkan ada tidaknya naungan dapat mempengaruhi penetasan telur. Pada lokasi yang bebas naungan menyebabkan tempat bertelur akan terpapar intensitas matahari secara langsung dan dapat menyebabkan suhu tempat peneluran menjadi lebih panas, sehingga reaksi kimia berlangsung lebih cepat dan masa inkubasi telur penyu lebih pendek (Nuitja, 1992). Jika dihubungkan dengan pemanasan global yang menyebabkan suhu bumi meningkat saat ini, keberadaan tempat peneluran pada daerah naungan vegetasi dapat menstabilkan suhu tempat peneluran agar tidak terlalu panas. Suhu inkubasi yang terlalu panas $\left(>30{ }^{\circ} \mathrm{C}\right)$ akan menghasilkan lebih banyak penyu betina. Jika semua tempat peneluran penyu memiliki suhu yang panas selama masa inkubasi, maka akan menyebabkan populasi penyu betina lebih tinggi dibandingkan dengan populasi penyu jantan, sehingga rasio kelamin penyu di alam tidak seimbang. Hal tersebut dapat mengurangi kesempatan penyu untuk melakukan reproduksi (Ibrahim et al. 2016).

\section{Jarak Tempat Peneluran Terhadap Vegetasi}

Hasil pengukuran jarak tempat peneluran penyu hijau (Chelonia midas) yang ditemukan terhadap vegetasi pantai (Gambar 7). 


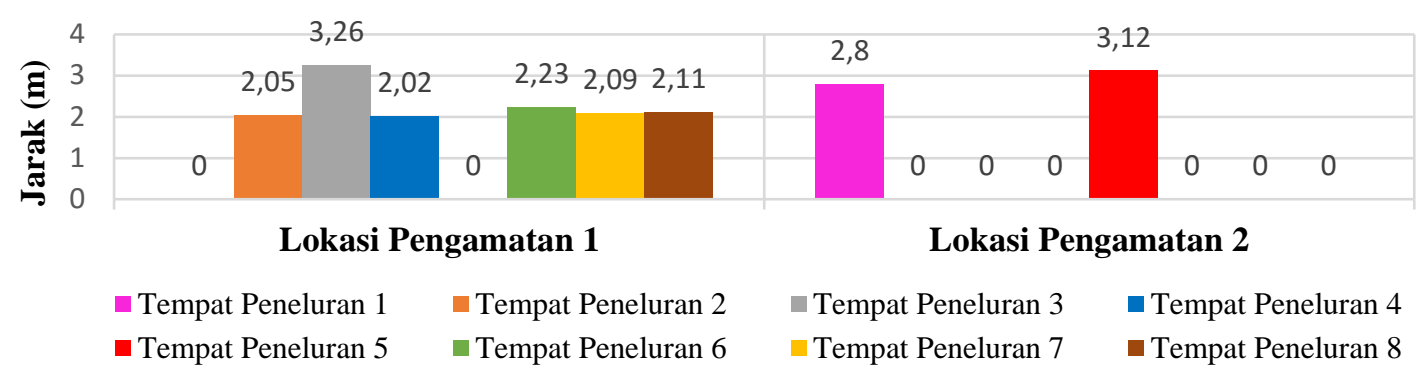

Gambar 7. Diagram jarak tempat peneluran terhadap vegetasi (Diagram of the distance of nesting sites to vegetation)

Berdasarkan hasil data Gambar 7, jarak tempat peneluran penyu hijau (Chelonia mydas) yang ditemukan terhadap vegetasi pantai berkisar antara 2,02 meter - 3,26 meter. Hal ini sesuai dengan pernyataan G. C Hays (1995) dalam Dewi et al. (2016), penyu hijau (C. mydas) akan melakukan aktivitas peneluran pada lingkungan bervegetasi sampai 2 meter masuk ke dalam zona vegetasi pantai. Tempat peneluran penyu hijau (C. mydas) lebih banyak ditemukan pada jarak 2-4 meter dari vegetasi terluar dan jauh dari pantai (Susilowati (2002) dalam Hidayat et al. (2017). Penyu hijau (C. mydas) akan memilih untuk meletakkan telur-telurnya dengan jarak yang cukup dekat dengan vegetasi dan jauh dari pantai, karena vegetasi dapat memberikan ketenangan dan rasa aman bagi telur penyu maupun induk penyu dari predator pada saat bertelur. Vegetasi juga dapat menstabilkan kondisi lingkungan sekitar tempat peneluran penyu hijau (C. mydas).

Kondisi Fisik Pantai Tempat Peneluran Penyu Hijau (Chelonia mydas)

Hasil pengukuran kondisi fisik pantai tempat peneluran penyu hijau (Chelonia mydas) yang ditemukan pada lokasi pengamatan (Tabel 2).

Tabel 2. Kondisi fisik pantai tempat peneluran penyu hijau (Chelonia mydas) (Beach physical conditions of nesting sites for green sea turtles (Chelonia mydas))

\begin{tabular}{|c|c|c|c|c|c|c|c|c|}
\hline \multirow{2}{*}{$\mathbf{T P}$} & \multirow{2}{*}{ Waktu } & \multirow{2}{*}{$\begin{array}{c}\text { Jarak } \\
\text { Pasang } \\
\text { Tertinggi } \\
\text { (m) }\end{array}$} & \multirow{2}{*}{$\begin{array}{c}\text { Kemiringan } \\
\text { Pantai }(\%)\end{array}$} & \multirow{2}{*}{$\begin{array}{c}\text { Tekstur } \\
\text { Substat } \\
(\%)\end{array}$} & \multicolumn{2}{|c|}{ Suhu $\left({ }^{\circ} \mathbf{C}\right)$} & \multicolumn{2}{|c|}{$\begin{array}{c}\text { Kelembaban } \\
(\%)\end{array}$} \\
\hline & & & & & Udara & Pasir & Udara & Pasir \\
\hline 1 & 00.14 WIB & 21,30 & 6,35 & 96,92 & 26,8 & 27,5 & 86 & 88 \\
\hline 2 & 04.35 WIB & 28,15 & 3,02 & 97,05 & 24,4 & 24,7 & 90 & 91 \\
\hline 3 & $22.35 \mathrm{WIB}$ & 26,20 & 3,10 & 96,94 & 23,72 & 23,97 & 89 & 88 \\
\hline 4 & $23.50 \mathrm{WIB}$ & 28,30 & 3,07 & 97,02 & 24,8 & 25,4 & 88 & 87 \\
\hline 5 & 04.40 WIB & 22,60 & 4,68 & 96,92 & 21,10 & 21,1 & 92 & 93 \\
\hline 6 & 20.39 WIB & 14,40 & 3,04 & 96,98 & 22,87 & 23,20 & 87 & 86 \\
\hline 7 & 23.37 WIB & 17,30 & 3,28 & 97,01 & 22,52 & 22,98 & 88 & 87 \\
\hline 8 & 23.51 WIB & 19,20 & 3,59 & 96,91 & 25,3 & 26,1 & 87 & 86 \\
\hline
\end{tabular}

Ket : TP = Tempat Peneluran 


\section{a. Jarak Tempat Peneluran Penyu} Hijau (Chelonia mydas) dari Pasang Tertinggi

Pantai peneluran penyu di TWA Tanjung Belimbing kebanyakan penyu yang naik/mendarat pada saat pasang tertinggi. Hasil pengukuran di lapangan, jarak tempat peneluran penyu hijau (Chelonia mydas) dari pasang tertinggi air laut berkisar antara 14,40 - 28,30 meter. Kawasan TWA Tanjung Belimbing merupakan kawasan dengan pantai yang cukup panjang dan luas. Menurut Putra et al, (2014), bahwa jarak tempat peneluran penyu yang tidak terlalu dekat dengan air laut akan menghindarkan tempat peneluran penyu dari rendaman air laut. Apabila tempat peneluran penyu terendam air laut maka akan menyebabkan gagalnya telur penyu untuk menetas.'

\section{b. Kemiringan Pantai Tempat Peneluran Penyu Hijau (Chelonia mydas)}

Kemiringan pantai merupakan faktor lingkungan yang sangat berpengaruh terhadap individu penyu untuk melakukan proses bertelur, selain dari suhu pantai dan vegetasi yang ada dipesisir pantai tersebut. Berdasarkan hasil pengukuran di lapangan diketahui bahwa, nilai kemiringan pantai di TWA Tanjung Belimbing pada tiap tempat peneluran penyu hijau (Chelonia mydas) berkisar antara $3.02 \%-6,35 \%$ dan memiliki kategori pantai yang landai. Menurut Manurung et al., (2015), pantai yang landai berkisaran (3-8\%) dan pantai yang miring berkisaran (8-16\%), sesuai dengan habitat dan peneluran penyu karena kondisi landai tersebut memudahkan penyu untuk mencapai tempat peneluran.
Kemiringan pantai sangat berpengaruh pada aksebilitas penyu hijau (C. mydas) untuk mencapai daerah yang cocok untuk bertelur. Semakin curam pantai maka akan semakin besar pula energi yang diperlukan penyu hijau (C. mydas) untuk naik dan bertelur. Kemampuan penyu hijau ( $C$. mydas) untuk melihat objek yang berada jauh di depan akan mengalami kesulitan jika kemiringan pantai terlalu curam. Hal ini dikarenakan, mata penyu hanya mampu berakomodasi dan melihat dengan baik pada sudut $150^{\circ}$ ke bawah (Putra et al. 2014).

\section{c. Tekstur Substrat Tempat Peneluran} Penyu Hijau (Chelonia mydas)

Pasir pantai pendaratan penyu di kawasan TWA Tanjung Belimbing memiliki jenis pasir berwarna putih kecoklatan. Hasil analisis tekstur substrat tiap tempat peneluran penyu hijau (Chelonia mydas) yang disajikan pada Tabel 2 di atas didominasi oleh pasir yaitu, $>90 \%$ dan selebihnya debu dan liat dengan jumlah yang sangat kecil. Menurut Wisnuhamidaharisakti, (1999) dalam Tambun et al. (2018), komposisi debu dan liat yang rendah memungkinkan pasir tidak lengket ketika penyu menggali lubang untuk tempat peneluran. Ukuran butir pasir digunakan sebagai data pelengkap dan perbandingan. Bentuk dari pasir halus dan kasar juga menentukan kemudahan penyu dalam menggali tempat peneluran. Ukuran pasir yang terlalu besar dan kasar akan menyulitkan penyu hijau (C. mydas) dalam menggali, karena semakin besar ukuran permukaan dan kerapatan sekumpulan partikel semakin besar gaya gesek yang ditimbulkan, maka semakin besar pula 
gaya usaha yang akan digunakan oleh penyu hijau (C. mydas) untuk membuat tempat penelurannya.

\section{d. Suhu Tempat Peneluran Penyu Hijau (Chelonia mydas)}

Hasil pengukuran suhu tempat peneluran penyu hijau (Chelonia mydas), yang dilakukan pada saat setelah penyu melakukan proses bertelur di kawasan TWA Tanjung Belimbing berkisar antara $21,10^{\circ} \mathrm{C}-26,8^{\circ} \mathrm{C}$ untuk suhu udara tempat peneluran penyu hijau (C. mydas), sedangkan suhu pasir berkisar antara 21,1 ${ }^{\circ} \mathrm{C}-27,5^{\circ} \mathrm{C}$. Pada malam hari suhu di luar tempat peneluran akan memiliki suhu yang lebih rendah dibandingkan di dalam tempat peneluran penyu. Permukaan pasir yang terkena radiasi matahari secara langsung menyebabkan suhu permukaan meningkat (Roemantyo et al, 2012). Hal ini menyebabkan suatu konduksi, yaitu proses perpindahan kalor dari permukaan pasir (suhu tinggi) ke pasir yang berada dibagian bawahnya (suhu rendah), begitupula sebaliknya. Hal ini sesuai dengan data pengukuran suhu yang dilakukan, bahwa pada malam hari kondisi suhu di luar (udara) lebih dingin dari pada suhu yang bawah (pasir) tempat peneluran penyu. Menurut Zarkasi et al. (2011), suhu tempat peneluran ini akan berpengaruh terhadap keberhasilan pengeraman telur-telur penyu yang membutuhkan kisaran suhu yang cukup agar embrio tidak membusuk dan dapat berkembang dengan baik. Pertumbuhan embrio sangat dipengaruhi oleh suhu. Embrio akan tumbuh optimal pada kisaran suhu antara $24-33{ }^{\circ} \mathrm{C}$, dan akan mati apabila di luar kisaran suhu tersebut. Menurut Dermawan et al., (2009), penelitian terhadap telur penyu yang ditempatkan pada suhu pasir berbeda menunjukan bahwa telur yang terdapat pada suhu pasir $32^{\circ} \mathrm{C}$ menetas dalam waktu 50 hari, sedangkan telur pada suhu $24{ }^{\circ} \mathrm{C}$ menetas dalam waktu lebih dari 80 hari. Kondisi lingkungan yang sangat mempengaruhi pertumbuhan embrio sampai penetasan yakni semakin tinggi suhu pasir, maka telur penyu akan lebih cepat menetas.

\section{e. Kelembaban Tempat Peneluran Penyu Hijau (Chelonia mydas)}

Hasil pengukuran kelembaban tempat peneluran penyu hijau (Chelonia mydas), yang dilakukan pada saat setelah penyu melakukan proses bertelur di kawasan TWA Tanjung Belimbing berkisar antara 86-92 \% untuk kelembaban udara tempat peneluran penyu hijau ( $C$. mydas), sedangkan untuk kelembaban pasir berkisar antara 86-93 \%. Kelembaban udara merupakan kapasitas udara untuk menampung uap air, semakin tinggi uap air maka semakin naik kelembaban udara pada tekanan uap aktual yang relatif tetap antara siang dan malam hari mengakibatkan kelembaban udara akan lebih rendah. Disamping itu, Kelembaban pasir merupakan faktor penting dalam pertumbuhan embrio dan penetasan telur. Pasir yang sesuai dengan kelembaban yang tepat mampu menyangga bentuk ruang pada telur. Oleh karena itu, induk penyu akan lebih memilih tempat dengan kelembaban yang tepat (Putra et al, 2014). Kelembaban pasir akan berpengaruh terhadap daya tetas telur penyu hijau ( $C$. mydas), jika kelembaban tinggi maka akan meningkatkan potensi mikroorganisme untuk berkembang dan akan merusak embrio. Jika kelembaban rendah maka telur yang diinkubasi akan kekeringan dan menyebabkan telur gagal menetas. 
Menurut Suswondo et al. (2004) dalam Benni et al. (2017), hubungan kelembaban dengan vegetasi yakni semakin luas naungan tempat peneluran penyu maka dapat meningkatkan kelembaban tempat peneluran penyu, karena naungan akan mereduk penguapan pada tempat peneluran penyu

\section{Kesimpulan}

Berdasarkan hasil penelitian tersebut, terdapat 12 tempat peneluran penyu hijau (Chelonia mydas) yang tersebar pada empat lokasi pengamatan dengan jumlah peneluran paling banyak ditemukan pada lokasi pengamatan 1 (bervegetasi dominasi cemara laut, pandan laut) yaitu, sebanyak 8 tempat peneluran dengan kondisi vegetasi pantainya yang beragam jenisnya. Jenisjenis tersebut antara lain adalah jenis tumbuhan berkayu seperti cemara laut (Casuarina equisetifolia), waru (Hibiscus tiliaceus), dan api-api (Avicennia sp). Selain itu, terdapat jenis tumbuhan semak seperti pandan laut (Pandanus tectorius), kamboja laut (Scaevola taccada) dan serunai laut (Melanthera biflora), serta jenis tumbuhan herba seperti tapak kuda (Ipomoea pes-caprae), alaban tanah (Vitex rotundifolia), rumput tembaga (Ischaemum muticum), bayam berduri (Amaranthus sp) dan bakung laut (Crynum asiaticum $\mathrm{L}$ ).

\section{Saran}

1. Tetap menjaga kondisi pantai di kawasan TWA Tanjung Belimbing.

2. Merehabilitasi lokasi pantai yang lain di kawasan TWA Tanjung Belimbing, agar sama dengan lokasi pengamatan 1.

3. Menjaga dari ancaman predator di kawasan TWA Tanjung Belimbing.

\section{DAFTAR PUSTAKA}

Anshary M, Setyawati TR, Yanti AH. 2014. Karakteristik Pendaratan Penyu Hijau (Chelonia mydas, Linnaeus 1758) di Pesisir Pantai Tanjung Kemuning Tanjung Api Dan Pantai Belacan Kecamatan Paloh Kabupaten Sambas. Jurnal Protobiont. 3 (2) : 232-239.

Balai Konservasi Sumber Daya Alam Kalimantan Barat. 2011. Buku Potensi Kawasan Taman Wisata Alam Tanjung Belimbing. Pontianak. Balai KSDA Kalimantan Barat.

Benni, Adi W, Kurniawan. 2017. Analisis Karakteristik Sarang Alami Peneluran Penyu. Akuatik Jurnal Sumberdaya Perairan. 11 (2) : ISSN 1978-1652.

Dahuri R. 2003. Keanekaragaman Hayati Laut Aset Pembangunan Berkelanjutan Indonesia. Jakarta : Gramedia Pustaka Utama.

Dermawan A, Nuitja N.S, Soedharma D, Matheus, Halim, Kusrini M.D, Lubis S.B, Alhanif R, Khazali, Murdiah M, Wahjuhardini P.L, Setiabudiningsih, Mashar A. 2009. Pedoman Teknis Pengelolaan Konservasi Penyu. Jakarta: Direktorat Konservasi dan Taman Nasional Laut, Direktorat Jenderal Kelautan Pesisir dan PulauPulau Kecil, Departemen Kelautan dan Perikanan RI.

Dewi. SA, Endrawati H, Redjeki S. 2016. Analisa Persebaran Sarang Penyu Hijau (Chelonia mydas) Berdasarkan Vegetasi Pantai Di Pantai Sukamade Merubetiri Jawa Timur. Buletin Oseanografi Marina. 5 (2) : 115-120. ISSN : 2089-3507.

Fachrul MF. 2003. Metode Sampling Bioekologi. Jakarta : Bumi Aksara. 
Hidayat YS, Elfidasari D, TS MQ. 2017. Struktur Vegetasi dan Karakteristik Habitat Peneluran Penyu Hijau (Chelonia mydas) di Kawasan Konservasi Penyu Pangumbahan Sukabumi. Jurnal Al-Azhar Indonesia Seri Sains dan Teknologi. 4(1).

Ibrahim A, Djumanto, Probosunu N. 2016. Sebaran Lokasi Peneluran Penyu Hijau (Chelonia mydas) di Pulau Sangalaki Kepulauan Derawan Kabupaten Berau. Jurnal Perikanan Universitas Gadjah Mada. 18 (2) : 39-46 : ISSN:0853-6384.

Istomo dan Dwisutono AN. 2016. Struktur dan Komposisi Tegakan Serta Sistem Perakaran Pertumbuhan Pada Kawasan Karst Di Taman Nasional Bantimurung-Bulusaraung Resort Pattunuang-Karaenta. Jurnal Silvikultur Tropika. 7 (1) : 56-67. ISSN : 2086-8227.

Manurung B, Erianto, Rifanjani S. 2015. Karakteristik Habitat Tempat Bertelur Penyu Di Kawasan Taman Wisata Alam Tanjung Belimbing Kecamatan Paloh Kabupaten Sambas. Jurnal Hutan Lestari. 4 (2) : 205-212.

Nuitja INS. 1992. Biologi dan Ekologi Pelestarian Penyu Laut. Bogor : Institut Pertanian Bogor Press.

Pradana F.A, Said S, Siahaan S. 2013. Habitat Tempat Bertelur Penyu Hijau (Chelonia mydas) di Kawasan Taman Wisata Alam Sungai Liku Kabupaten Sambas Kalimantan Barat. Jurnal Hutan Lestari. Vol 1.

Putra BA, Wibowo KE, Rejeki S. 2014. Studi Karakteristik Biofisik Habitat Peneluran Penyu Hijau (Chelonia mydas) di Pantai Paloh Sambas Kalimantan Barat. Journal Of
Marine Research. Vol 3(3) : 173181.

Roemantyo, Nastiti AS, Wiadnyana NN. 2012. Struktur dan Komposisi Vegetasi Sekitar Sarang Penyu Hijau (Chelonia mydas Linnaeus) Pantai Pangumbahan Sukabumi Selatan Jawa Barat. Berita Biologi. 11 (3).

Tambun PC, Wahyuningsih H, Soemaryono Y. 2018. Karakteristik Bio-Fisik Habitat Pantai Peneluran Terhadap Tingkat Keberhasilan Penetasan Telur Penyu Hijau (Chelonia mydas) di Pulau Penyu Pesisir Selatan Provinsi Sumatera Barat. Jurnal Aquacoastmarine. 6(1) : 46-56.

Zarkasi M, Efrizal T, Zen LW. 2011. Analisis Distribusi Sarang Penyu Berdasarkan Karakteristik Fisik Pantai Pulau Wie Kecamatan Tambelan Kabupaten Bintan. Bintan Universitas Maritim Raja Ali Haji. 3 (1) : 26-54. 